\title{
A Study of Fast and Metastable Dissociations of Adenine-Thymine Binary-Base Oligonucleotides by Using Positive-Ion MALDI-TOF Mass Spectrometry
}

\author{
T.-W. Dominic Chan, Y. M. Eva Fung, and Y. C. Leo Li \\ Department of Chemistry, The Chinese University of Hong Kong, Shatin, N.T., Hong Kong
}

In the present study, fast and metastable dissociations of a number of adenine-thymine binary-base oligonucleotides under the conditions of UV matrix-assisted laser desorption/ ionization mass spectrometry were investigated. 2-Aminobenzoic acid/ammonium fluoride $\left(\mathrm{ABA} / \mathrm{NH}_{4} \mathrm{~F}\right)$ matrix system was used. The spectra obtained under metastable and fast dissociation conditions exhibit distinctive dissociation products. From the post-source-decay analysis, all oligonucleotides underwent predominantly metastable dissociations at the 3' C-O linkages to form $\left[\mathrm{a}_{\mathrm{n}}-\mathrm{B}\right]^{+}$and $\mathrm{w}_{\mathrm{n}}^{+}$complimentary ion series. Based on the present results, the so-called " $\left[\mathrm{w}_{\mathrm{n}}+80\right]^{+}$" ions were postulated to be the complimentary $\left[\mathrm{z}_{(8-\mathrm{n})} \mathrm{AH}\right]^{+}$ions rather than the expected phosphate rearrangement products. In addition, these oligonucleotides were found to generate fast dissociation products of $b_{n}^{+}, d_{n}^{+}, w_{n}^{+}$and $y_{n}^{+}$ions through backbone cleavages at 5' C-O, 5' O-P, 3' C-O and 3' P-O linkages, respectively. Product ion series formed under PSD conditions were not observed. The implications of this mutually exclusive occurrence of the two sets of fragment ions under fast and metastable conditions using $\mathrm{ABA} / \mathrm{NH}_{4} \mathrm{~F}$ matrix would be discussed. A model of ion activation under UV-MALDI conditions was also proposed. (J Am Soc Mass Spectrom 2002, 13, 1052-1064) (c) 2002 American Society for Mass Spectrometry

S tructural characterization of short-chain nucleic acids has recently attracted much attention. They can serve as useful tools in molecular biology, as gene probes for diagnosis, or as potential drugs interacting at the level of nucleic acids. Typical short-chain DNA sequencing methods involve the use of the enzymatic or chemical cleavage algorithms [1-3] to produce DNA ladder products. The DNA fragments generated are then separated and identified by HPLC or gel electrophoresis. Structural verification of oligonucleotides using these methods is time-consuming and is sometimes impossible for modified oligonucleotides. Recent developments in matrix-assisted laser desorption/ionization time-of-flight (MALDI-TOF) mass spectrometry [4-9] have stimulated interest in replacing HPLC/gel electrophoresis by mass spectrometry in order to increase the speed and accuracy of the sequence determination. However, this approach still needs the time-consuming chemical or enzymatic reactions for producing sequence specific fragment ladder. A potentially more efficient method would be to obtain the DNA sequence information from fragmentation

Published online July 24, 2002

Address reprint requests to Dr. T.-W. Dominic Chan, Department of Chemistry, The Chinese University of Hong Kong, Shatin, Hong Kong. E-mail: twdchan@cuhk.edu.hk patterns in mass spectrometry through dissociation. In the present study, we attempt to evaluate the potential use of two rather direct mass spectrometric sequencing methods, namely fast and metastable dissociations for DNA sequence analysis.

Fast fragmentation differs from metastable dissociation at the time of bond cleavage after the excitation of the precursor ions. In mass spectrometry, fragments are produced in a much shorter time as compared to the ion extraction time of the mass spectrometer. In the case of time-of-flight mass spectrometer, these fragment ions are therefore registered at their true masses in both linear and reflectron mode of detection. Metastable fragments, on the other hand, are usually formed at a much longer time scale (i.e., $>500 \mathrm{~ns}$ ) and are formed beyond the ion source region and before reaching the detector. Since the metastable ions are formed with the same velocity of the precursor ions, they are registered at the same mass-to-charge ratio of the precursor ion in a linear TOF instrument. In a reflectron TOF instrument, most of the metastable ions are not detected because of the energy-mismatch for correct ion reflection to the detector. Under proper reflectron settings, metastable ions with masses close to the precursor ion can sometimes be reflected to the detector and be recorded. However, the flight time (and the registered masses) for these ions would be shifted to lower values 
as compared to the precursor ion due to the shorter flight path in the reflector mirror. Metastable ions of lower masses can only be tuned to correct reflection flight path by properly reducing the reflector potential. Measurement of these metastable fragment ions using reflectron TOF instrument with variable reflector potentials is known as "post-source decay" (PSD) analysis [10-11]. Judging from the time required for dissociation, the precursor ions which undergo fast and metastable dissociations differ from their internal energies. Precursor ions with lower internal energies have a greater chance of undergoing cleavages via metastable dissociation pathways as compared to that of fast dissociation. Since polyatomic ions have a large number of unimolecular dissociation pathways, the resultant fragment ion pattern might give an indirect indication of the relative height of energy barriers for different dissociation pathways.

In MALDI experiments, the internal energy of the desorbed ions depends on (1) the selection of matrix and co-matrices [12-13]; (2) the laser wavelength [14], (3) laser irradiance [15]; and (4) the sample preparation methods [16]. Most of the commonly used matrices for DNA analysis, such as 3-hydroxypicolinic acid (HPA) and picolinic acid (PA), lead only to metastable dissociation [6,17]. Some matrix materials can however generate measurable amount of fast fragment ions in addition to metastable fragment ions. Examples include 2,5-dihydroxybenzoic acid (DHB) [18], 2-amino-5-nitropyridine (ANP) [12], 2,4,6-trihydroxyacetophenone [19-20] and 2-amino-benzoic acid (ABA) [20]. In this article, we compare the fragmentation patterns of several combinations of adenine-thymine binary-base octamers of DNA under both fast and metastable dissociation conditions using $\mathrm{ABA} / \mathrm{NH}_{4} \mathrm{~F}$ matrix system. Adenine-thymine binary-base oligonucleotides were used for the present study due to the difference in the stability of these nucleobases. Adenine is known to be a labile nucleobase; whereas thymine is not. By using different sequential arrangements, different channels of dissociation could then be studied. ABA was used due to its ability to induce substantial fast dissociation while preserving a fairly intense molecular ion signal. Ammonium fluoride has previously been described to induce signal enhancement for 5-amino-2-nitropyridine (ANP), 2,5-dihydroxybenzoic acid (DHB) and 3-hyropicolinic acid (HPA) [12]. Consistently, $\mathrm{NH}_{4} \mathrm{~F}$ was also found to exert substantial signal enhancement effect for the analysis of oligonucleotide under ABA matrix.

The main objective of this investigation is to compare and contrast the patterns of fragmentation under prompt and metastable conditions and to identify factors that influence the dissociation of oligonucleotides. With a better understanding of the dissociation of oligonucleotides under MALDI conditions, it is our goal to develop experimental conditions in which sequence information of short-chain DNA fragments ( $<20$-mers) can be assigned unambiguously from the MALDI mass spectrum.

\section{Experimental}

Oligonucleotides $\mathrm{pd}(\mathrm{TA})_{4}, \mathrm{~d}(\mathrm{TA})_{4}, \mathrm{~d}(\mathrm{TA})_{4} \mathrm{p}, \mathrm{pd}(\mathrm{AT})_{4}$, $\mathrm{d}(\mathrm{AT})_{4}, \mathrm{~d}(\mathrm{AT})_{4} \mathrm{p}, \mathrm{d}\left(\mathrm{T}_{4} \mathrm{~A} 4\right)$ and $\mathrm{d}\left(\mathrm{A}_{4} \mathrm{~T}_{4}\right)$ were custom synthesized by Biosynthesis (Lewisville, TX, USA). Oligonucleotide sequences are written in the $5^{\prime}$ to $3^{\prime}$ direction. 2-Aminobenzoic acid (ABA) and 3-hydropicolinic acid (HPA) were purchased from Aldrich (Milwaukee, Wisconsin, USA). Protein calibrants and other chemical reagents were purchased commercially and were used without further purification.

Oligonucleotides were dissolved in ultra-pure water (18 $\mathrm{M} \Omega$ ) to give concentrations of $40 \mathrm{pmol} / \mu \mathrm{L}$. Saturated matrix solution was prepared by dissolving excess amount of 2-aminobenzoic acid in acetonitrile: water (1:1). Excess matrix material was settled using a microcentrifuge. The $\mathrm{pH}$ of the saturated ABA and HPA matrices were 3.9 and 3.6, respectively. Solution of ammonium fluoride was prepared in ultra-pure water to give a concentration of $100 \mathrm{nmol} / \mu \mathrm{L}$. Equal volume of matrix and ammonium fluoride solutions were mixed. Equal portions of mixed-matrix and oligonucleotide solution were combined to give the final sample solution with an analyte-to-ammonium salt ratio of 1:8000. $1 \mu \mathrm{L}$ of the resulting solution was applied onto the sample plate and was dried at ambient conditions before inserting into the MALDI-TOF mass spectrometer for analysis.

All MALDI mass spectra were acquired in positiveion mode by using a Bruker Biflex time-of-flight mass spectrometer (Franzen, Germany). The instrument was equipped with a nitrogen laser (Laser Science Inc., Newton, MA, USA) operating at 337-nm. The laser pulse duration was roughly 3 ns. The total acceleration voltage was set to $19.0 \mathrm{kV}$. The delayed extraction was operated with a switched voltage of $4.75 \mathrm{kV}$ and a fixed delay of $\sim 100 \mathrm{~ns}$. The reflector mirror was set at +20.0 $\mathrm{kV}$. In all PSD experiments, the precursor ion was selected by using a timed precursor-ion selector. Laser fluence was carefully adjusted using a gradient neutral density filter to obtain the maximum signal-to-noise ratios. Each fast dissociation spectrum was a sum of 10 laser shots at a single sampling position. Several positions $(>5)$ from an individual sample were examined. All prompt dissociation experiments were repeated five times to ensure spectral reproducibility. Calibration was done externally by using $\mathrm{d}(\mathrm{T})_{4}, \mathrm{~d}(\mathrm{~T})_{8}$ and $\mathrm{d}(\mathrm{T})_{12}$ using HPA matrix. For post-source-decay (PSD) analysis, the potentials of the reflector mirror were gradually stepped down from $+20 \mathrm{kV}$ to $+0.57 \mathrm{kV}$ in nineteen steps. In each voltage step, 150 to 200 shots were summed to give a spectral segment of satisfactory signal-to-noise ratios. The final PSD spectrum was pasted by using the Xtof 3.0 software. Calibration was done using ACTH with DHB matrix. All experiments were repeated three times to ensure spectral reproducibility. 

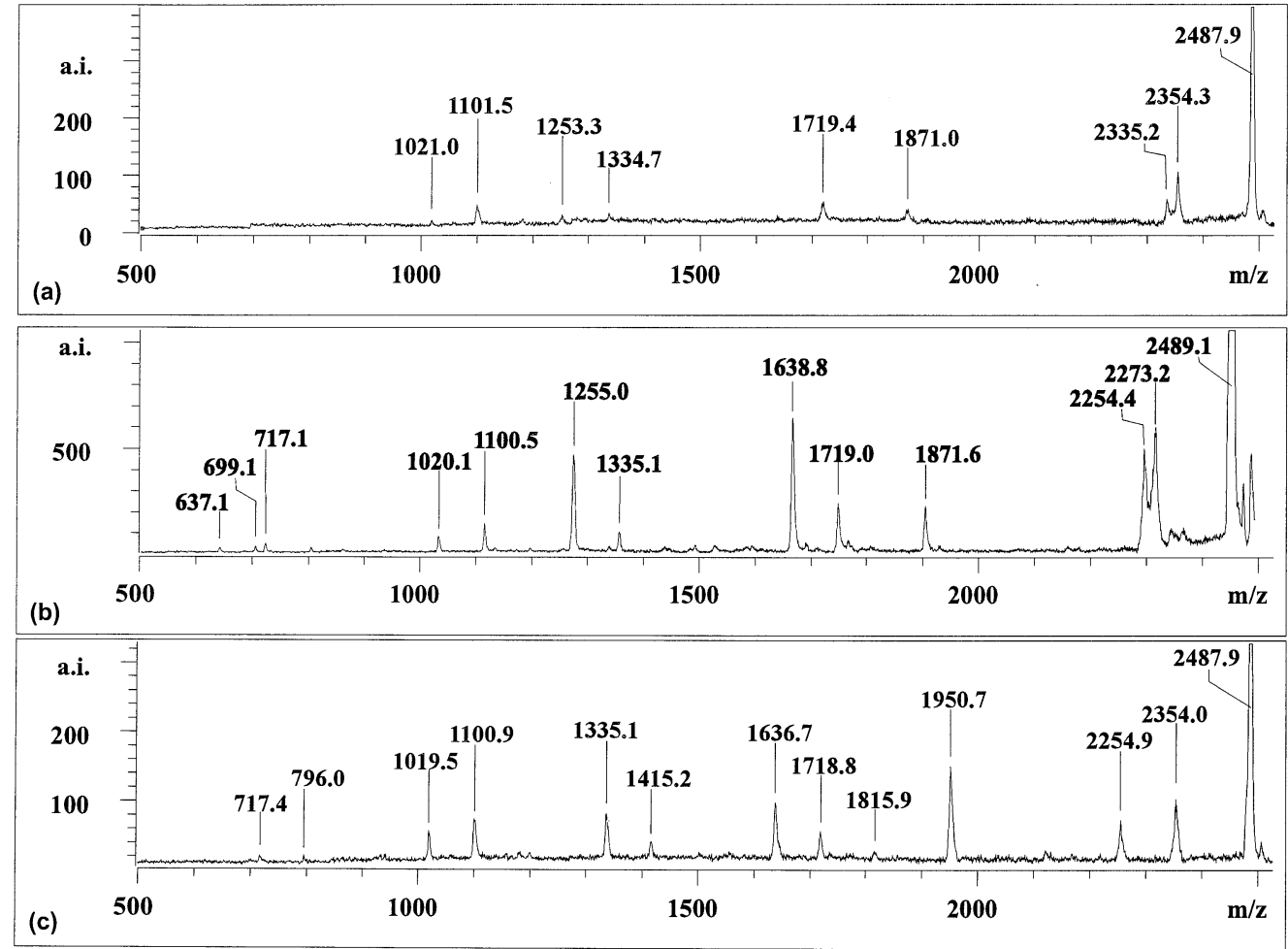

Figure 1. Post-source-decay mass spectra of protonated DNA cations (a) pd(TATATATA); (b) d(TATATATA); and (c) d(TATATATA)p. The precursor ions were obtained using $\mathrm{ABA} / \mathrm{NH}_{4} \mathrm{~F}$ matrix.

\section{Results and Discussion}

In contrast to other commonly used nucleic acid matrices (e.g., HPA), UV-MALDI analysis of oligonucleotides in positive-ion mode by using 2-aminobenzoic acid/ ammonium fluoride matrix shows substantial fragmentation in both standard reflectron mass spectra and post-source decay mass spectra. Throughout this article, the product ions are assigned with nomenclature proposed by McLuckey and co-workers [21].

\section{Metastable Dissociation}

Figure 1 shows the post source decay (PSD) mass spectra of pd(TATATATA), d(TATATATA) and d(TATATATA)p. The spectral information is summarized in Table 1 for comparison. Because of the symmetry of the oligonucleotides, product ions derived from different cleavages might result in the fragment peaks that are not distinguished in mass from each other, i.e., mass-composition redundancies. In all cases, different possible fragment ions were included in the table for reference. Ions superscripted with an ' $a$ ' are possible cleavage products of pd(TATATATA) only. All oligonucleotides were found to have substantial loss of labile nucleobase, i.e., adenine, to form abundance $[\mathrm{M}-\mathrm{AH}]^{+}$. In contrast to the previous studies using smaller oligonucleotides [22,23] loss of thymine was not found. Apart from the $[\mathrm{M}-\mathrm{AH}]^{+}$ions, series of $\left[\mathrm{a}_{\mathrm{n}}-\mathrm{AH}\right]^{+}$and $\mathrm{w}_{\mathrm{n}}^{+}$ions were observed, where $\mathrm{n}$ is an even number.
Formation of these backbone fragments is consistent with the presence of the labile adenine base in the adjacent 5 ' sugar ring. It is also important to note that none of the corresponding $a_{n}^{+}$ions were observed. While the exact mechanism(s) of oligonucleotides fragmentation remains a controversial issue [24,25], our observations agree with the earlier postulation $[26,27]$ that loss of the neutral base is a pre-requisite for the corresponding backbone cleavage at the $3^{\prime} \mathrm{C}-\mathrm{O}$ linkage. Comparing the PSD spectrum of 3' phosphylated oligonucleotide to that of other oligonucleotides, no [M-AH$\mathrm{H}_{2} \mathrm{O}^{+}$was observed. Intense fragment ions corresponding to $[\mathrm{M}-\mathrm{AH}-\mathrm{P}]^{+}$was however found. This implies that the $\left[\mathrm{M}-\mathrm{AH}-\mathrm{H}_{2} \mathrm{O}\right]^{+}$ions were likely be originated from the 3,4-elimination of $\mathrm{H}_{2} \mathrm{O}$ at the 3'terminal sugar moiety after the loss of the labile adenine. Therefore, $[\mathrm{M}-\mathrm{AH}-\mathrm{P}]^{+}$and $\left[\mathrm{M}-\mathrm{AH}-\mathrm{H}_{2} \mathrm{O}\right]^{+}$can be regarded as $\left[\mathrm{a}_{8}-\mathrm{AH}\right]^{+}$.

Apart from the $\left[\mathrm{a}_{\mathrm{n}}-\mathrm{AH}\right]^{+}$and $\mathrm{w}_{\mathrm{n}}^{+}$ion series, it was noted that several $\mathrm{w}_{\mathrm{n}}^{+}$ions were accomplished with minor peaks at $80 \mathrm{u}$ higher. Based on the mass correlation, these fragment ions could be attributed either $\left[\mathrm{w}_{\mathrm{n}}+\mathrm{HPO}_{3}\right]^{+}$or $\left[\mathrm{z}_{\mathrm{n}}-\mathrm{AH}\right]^{+}$. Similar ions have been observed previously [28] in the CID spectra of oligonucleotides in negative-ion mode and were attributed to be $\left[\mathrm{w}_{\mathrm{n}}+\mathrm{HPO}_{3}\right]^{-}$ions. The mechanism of formation was postulated to proceed through the transfer of the 5'terminal phosphate group from the $\left[\mathrm{w}_{\mathrm{n}+1}\right]^{-}$to the $\mathrm{w}_{\mathrm{n}}^{-}$, with concomitant elimination of a reduced nucleoside. 
Table 1. Summary of positive-ion post-source-decay (PSD) mass spectra of pd(TATATATA), d(TATATATA) and d(TATATATA)p ${ }^{\text {a }}$

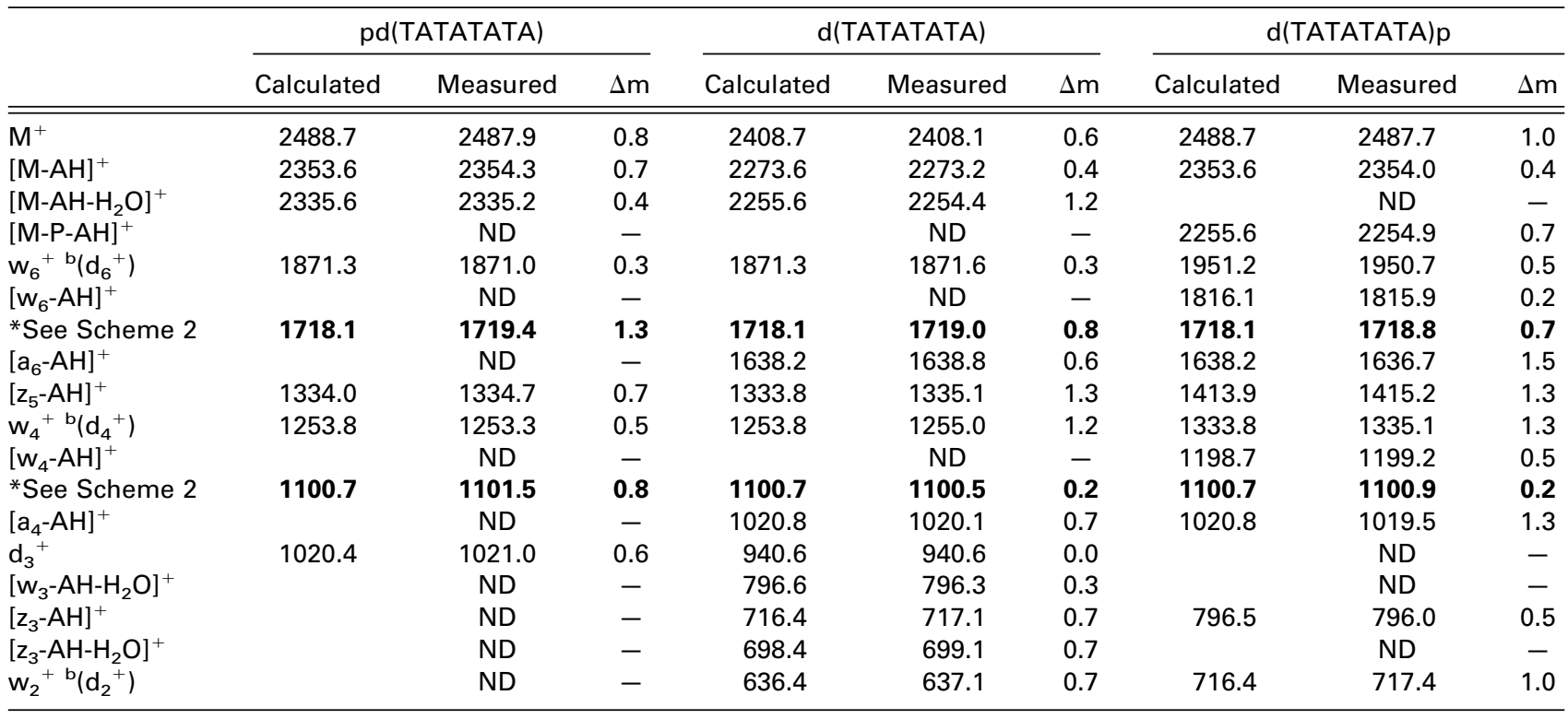

all data are calculated and measured with average masses.

bapply to pd(TATATATA) only. \%ND = not detected.

In the present PSD spectra, it is noted that there seems to be a positional selectivity in the generation of these fragment ions. These so-called " $\left[\mathrm{w}_{\mathrm{n}}+80\right]^{+"}$ ions occur only when the corresponding $\mathrm{w}_{\mathrm{n}}^{+}$ions are formed, where $\mathrm{n}$ is an even number. Because of the alternative arrangement of thymine- and adenine-containing nucleotides in the oligonucleotides, formation of $\left[\mathrm{w}_{\mathrm{n}+1}\right]^{+}$ ions was not favored and was indeed not observed. In addition, none of the corresponding $\left[\mathrm{w}_{\mathrm{n}-1}+80\right]^{+}$ions were observed. These findings have led to a conclusion that the observed " $\left[\mathrm{w}_{\mathrm{n}}+80\right]^{+\prime}$ ions were actually originated from $\left[\mathrm{z}_{\mathrm{m}}-\mathrm{AH}\right]^{+}$ions, where $\mathrm{m}$ is an odd number. Based on the positional selectivity, it is postulated that the loss of neutral base could also initiate the corresponding backbone cleavage at the 5' C-O linkage. Scheme 1 illustrates these two possible fragmentation pathways for backbone cleavage. The presence of $d_{3}^{+}$ and $\mathrm{d}_{5}^{+}$ions (but not $\mathrm{d}_{4}^{+}$nor $\mathrm{d}_{6}^{+}$) in Figure $1 \mathrm{a}-\mathrm{c}$ is consistent with the present postulation. Although there is no direct evidence, it is postulated that the 3 ' C-O and 5' C-O backbone cleavages are competitive processes. The relative high intensity of the fragment ions originated from 3' C-O cleavage might be attributed to the formation of a stable aromatic furan ring at the 3 '-end. The analogous reaction sequence at the 5 '-end (1,2- and 4,5-elimination) yields only a comparatively less stable conjugated system.

Table 2 summarizes the mass spectral information of the post source decay spectra of pd(ATATATAT), d(ATATATAT) and d(ATATATAT)p. Consistent with the swapping of the T-A sequence, all oligonucleotides shows $\left[\mathrm{a}_{\mathrm{m}}-\mathrm{AH}\right]^{+}$and $\mathrm{w}_{\mathrm{m}}^{+}$ions, where $\mathrm{m}$ is an odd number; and $\left[z_{n}-A H\right]^{+}$and $d_{n}^{+}$ions, where $n$ is an even number. Since the nucleobase at the $3^{\prime}$-terminal sugar is a non-labile thymine in these oligonucleoide series, fragment ions corresponding to [M-AH- $\left.\mathrm{H}_{2} \mathrm{O}\right]^{+},[\mathrm{M}-\mathrm{AH}-$ $\mathrm{P}]^{+},\left[\mathrm{M}-\mathrm{TH}-\mathrm{H}_{2} \mathrm{O}\right]^{+}$and $[\mathrm{M}-\mathrm{TH}-\mathrm{P}]^{+}$species were not found, as expected.

Finally, it is interesting to note that the PSD spectra of oligonucleotides tested in Table 1 and 2 shows two common fragment peaks at $\mathrm{m} / \mathrm{z} 1100$ and $\mathrm{m} / \mathrm{z} 1718$ (as marked with $\left.{ }^{* \prime}\right)$. Although the formation of these two product ions from pd(TATATATA) and d(ATATATAT)p ions can easily be explained on the basis of the formation of $\left[\mathrm{a}_{4}-\mathrm{AH}\right]^{+} /\left[\mathrm{a}_{6}-\mathrm{AH}\right]^{+}$and $\left[\mathrm{z}_{4^{-}}\right.$ $\mathrm{AH}]^{+} /\left[\mathrm{z}_{6}-\mathrm{AH}\right]^{+}$product ions respectively (see Scheme 2 ), occurrence of these fragment peaks in the PSD spectra of other oligonucleotide ions could only be explained by the generation of internal fragments. Scheme 2 illustrates several possible modes of cleavage. Basically, all species can be explained by using a model of double cleavage in $\mathrm{w}_{\mathrm{n}}^{+} /\left[\mathrm{a}_{\mathrm{n}}-\mathrm{AH}\right]^{+}$type, where $\mathrm{n}$ is either an even number (for pd(TATATATA), d(TATATATA) and d(TATATATA)p) or an odd number (for pd(ATATATAT), d(ATATATAT) and d(ATATATAT)p). These internal ions have previously been observed in the study of the prompt dissociation of some oligonucleotides under IR-MALDI conditions, i.e., the so-called $Z^{*}$-ions [17]. Since these double cleavages occur at a distance from each other, charge-remote mechanism [22] is believed to play a significant role in the backbone cleavage.

\section{Fast Dissociation}

In attempt to improve the accuracy of mass measurement, the fast dissociation spectra of adenine-thymine oligonucleotides were measured with standard reflectron time-of-flight instrument. To avoid spectral complications arising from sample impurities, the purities 


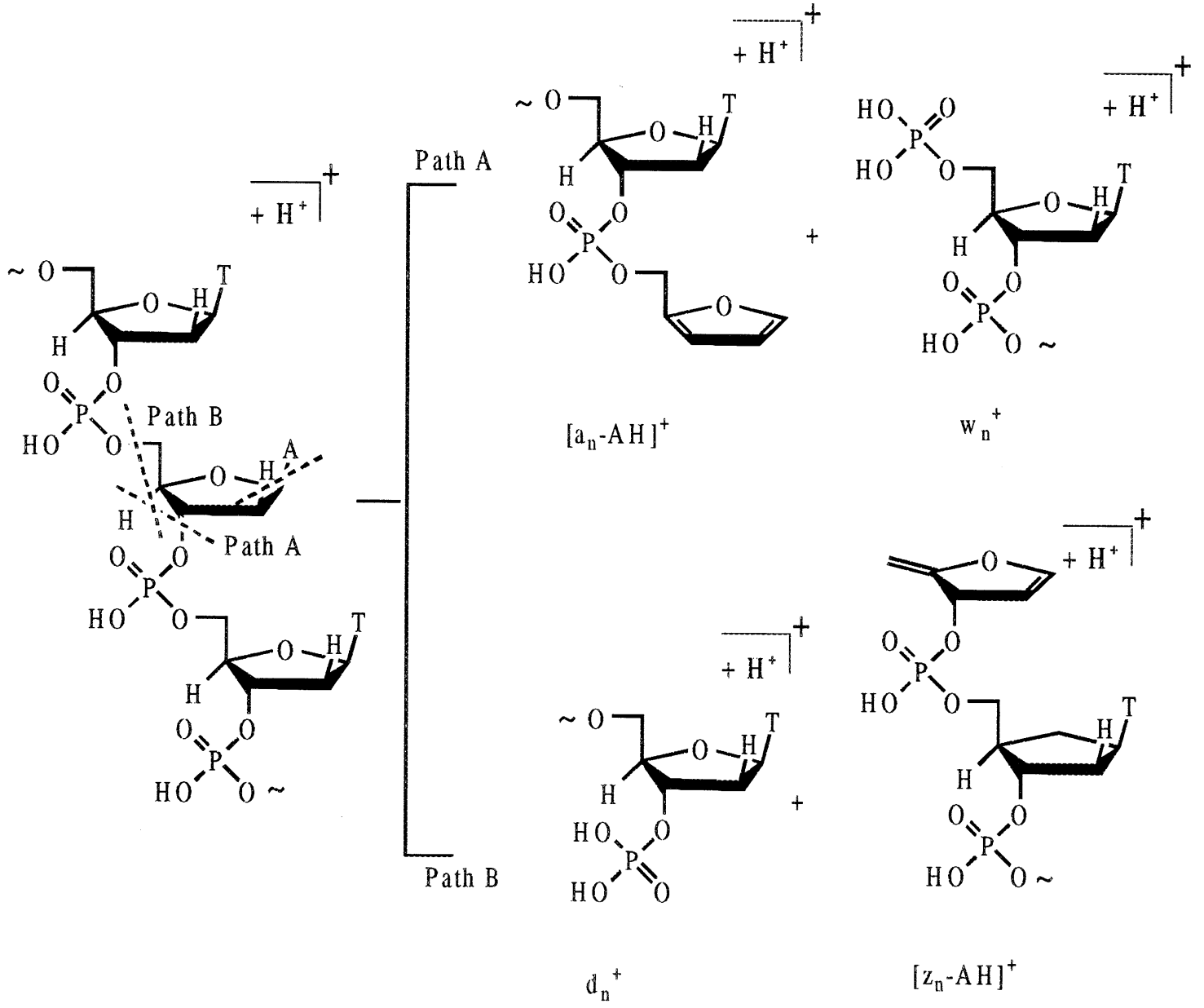

Scheme 1

of oligonucleotides were clarified by using $\mathrm{HPA} / \mathrm{NH}_{4} \mathrm{~F}$ prior to the fragmentation studies. Figure $2 a$ and $b$ show typical reflectron mass spectra of d(TATATATA) using $\mathrm{ABA} / \mathrm{NH}_{4} \mathrm{~F}$ and $\mathrm{HPA} / \mathrm{NH}_{4} \mathrm{~F}$ matrices, respec- tively. Both spectra were obtained at the same laser fluence. With proper spectral calibration, it is clearly demonstrated that peaks marked with asterisks were fragment ions derived by fast dissociation of the

Table 2. Summary of positive-ion post-source-decay (PSD) mass spectra of pd(ATATATAT), d(ATATATAT) and d(ATATATAT)p ${ }^{a}$

\begin{tabular}{|c|c|c|c|c|c|c|c|c|c|}
\hline & \multicolumn{3}{|c|}{ pd(ATATATAT) } & \multicolumn{3}{|c|}{ d(ATATATAT) } & \multicolumn{3}{|c|}{ d(ATATATAT)p } \\
\hline & Calculated & Measured & $\Delta \mathrm{m}$ & Calculated & Measured & $\Delta \mathrm{m}$ & Calculated & Measured & $\Delta \mathrm{m}$ \\
\hline $\mathrm{M}^{+}$ & 2488.7 & 2487.5 & 1.2 & 2408.7 & 2408.1 & 0.6 & 2488.7 & 2487.7 & 1.0 \\
\hline$[\mathrm{M}-\mathrm{AH}]^{+}$ & 2353.6 & 2354.7 & 1.1 & 2273.6 & 2274.5 & 0.9 & 2353.6 & 2354.1 & 0.5 \\
\hline$w_{7}^{+}$ & 2175.5 & 2175.9 & 0.4 & 2175.5 & 2174.7 & 0.8 & 2255.4 & 2255.0 & 0.4 \\
\hline$\left[\mathrm{w}_{7}-\mathrm{AH}\right]^{+}$ & & ND & - & 2040.4 & 2041.3 & 0.8 & 2120.3 & 2121.7 & 1.4 \\
\hline$\left[\mathrm{a}_{7}-\mathrm{AH}\right]^{+}$ & 2031.4 & 2032.4 & 1.0 & 1951.4 & 1952.1 & 0.7 & 1951.4 & 1952.0 & 0.6 \\
\hline *See Scheme 2 & 1718.1 & 1718.8 & 0.7 & 1718.1 & 1719.1 & 1.0 & 1718.1 & 1718.9 & 0.8 \\
\hline$\left[\mathrm{z}_{6}-\mathrm{AH}\right]^{+}$ & 1638.2 & 1638.5 & 0.3 & 1638.9 & 1638.9 & 0.00 & & ND & - \\
\hline $\mathrm{w}_{5}^{+}$ & 1558.0 & 1558.2 & 0.2 & 1558.0 & 1558.7 & 0.7 & 1638.0 & 1638.7 & 0.7 \\
\hline$\left[\mathrm{w}_{5}-\mathrm{AH}\right]^{+}$ & & ND & - & 1422.9 & 1422.9 & 0.00 & & ND & - \\
\hline$\left[\mathrm{a}_{5}-\mathrm{AH}\right]^{+}$ & 1413.9 & 1415.3 & 1.4 & 1334.0 & 1335.1 & 1.1 & 1334.0 & 1335.6 & 1.6 \\
\hline $\mathrm{d}_{4}^{+}$ & & ND & - & & ND & - & 1253.8 & 1252.7 & 1.1 \\
\hline${ }^{*}$ See Scheme 2 & 1100.7 & 1101.3 & 0.6 & 1100.7 & 1100.1 & 0.4 & 1100.7 & 1100.5 & 0.2 \\
\hline$\left[\mathrm{z}_{4}-\mathrm{AH}\right]^{+}$ & 1020.8 & 1019.7 & 1.1 & 1020.8 & 1020.2 & 0.6 & & ND & - \\
\hline $\mathrm{w}_{3}{ }^{+}$ & 940.6 & 940.9 & 0.3 & 940.6 & 941.0 & 0.4 & 1020.6 & 1021.1 & 0.5 \\
\hline$\left[\mathrm{a}_{3}-\mathrm{AH}\right]^{+}$ & 796.5 & 796.9 & 0.4 & & ND & - & & ND & - \\
\hline
\end{tabular}

${ }^{a}$ all data are calculated and measured with average masses. $\% \mathrm{ND}=$ not detected. 
J Am Soc Mass Spectrom 2002, 13, 1052-1064

Adenine-Thymine Binary-Base Oligonucleotides

1057

(a) For $\left(X^{\prime} /\right)$ Xd(TATATATA)X, where $X$ is either $-\mathrm{OH}$ or $-\mathrm{HPO}_{3}$ and $\mathrm{X}^{\prime}$ is $-\mathrm{HPO}_{3}$.

$m / z 1100.7$
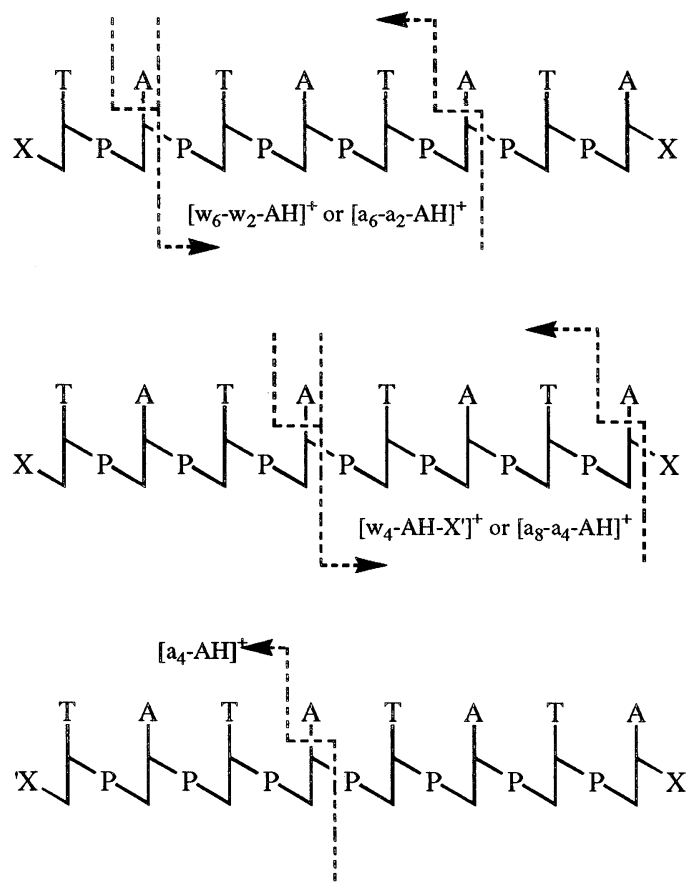

$m / z$ 1718.1
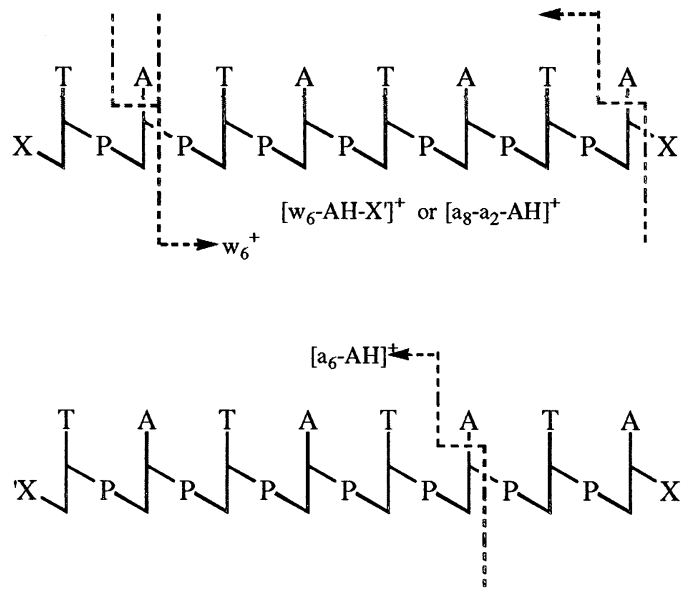

(b) For $\mathrm{Xd}(\mathrm{ATATATAT}) \mathrm{X}\left(/ \mathrm{X}^{\prime}\right)$, where $\mathrm{X}$ is either $-\mathrm{OH}$ or $-\mathrm{HPO}_{3}$ and $\mathrm{X}^{\prime}$ is $-\mathrm{HPO}_{3}$.

$m / z 1100.7$
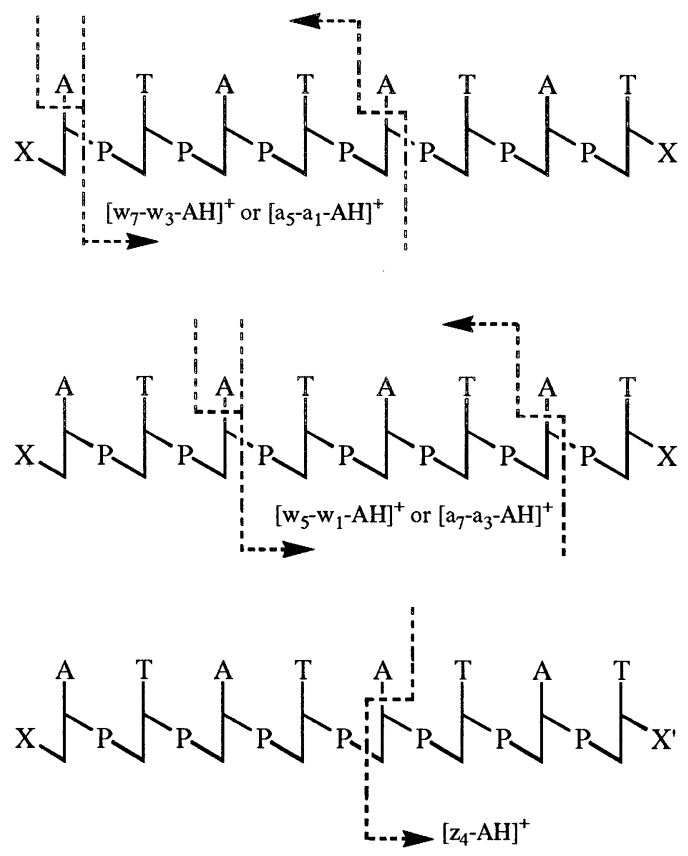

$m / z 1718.1$
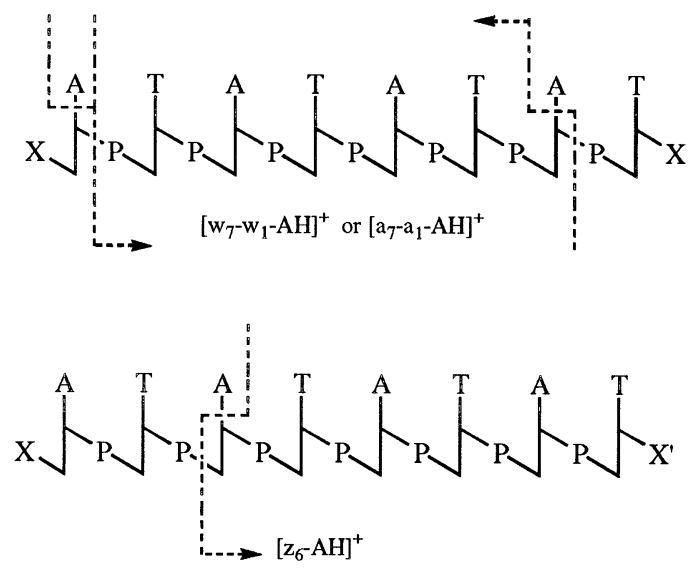

Scheme 2 


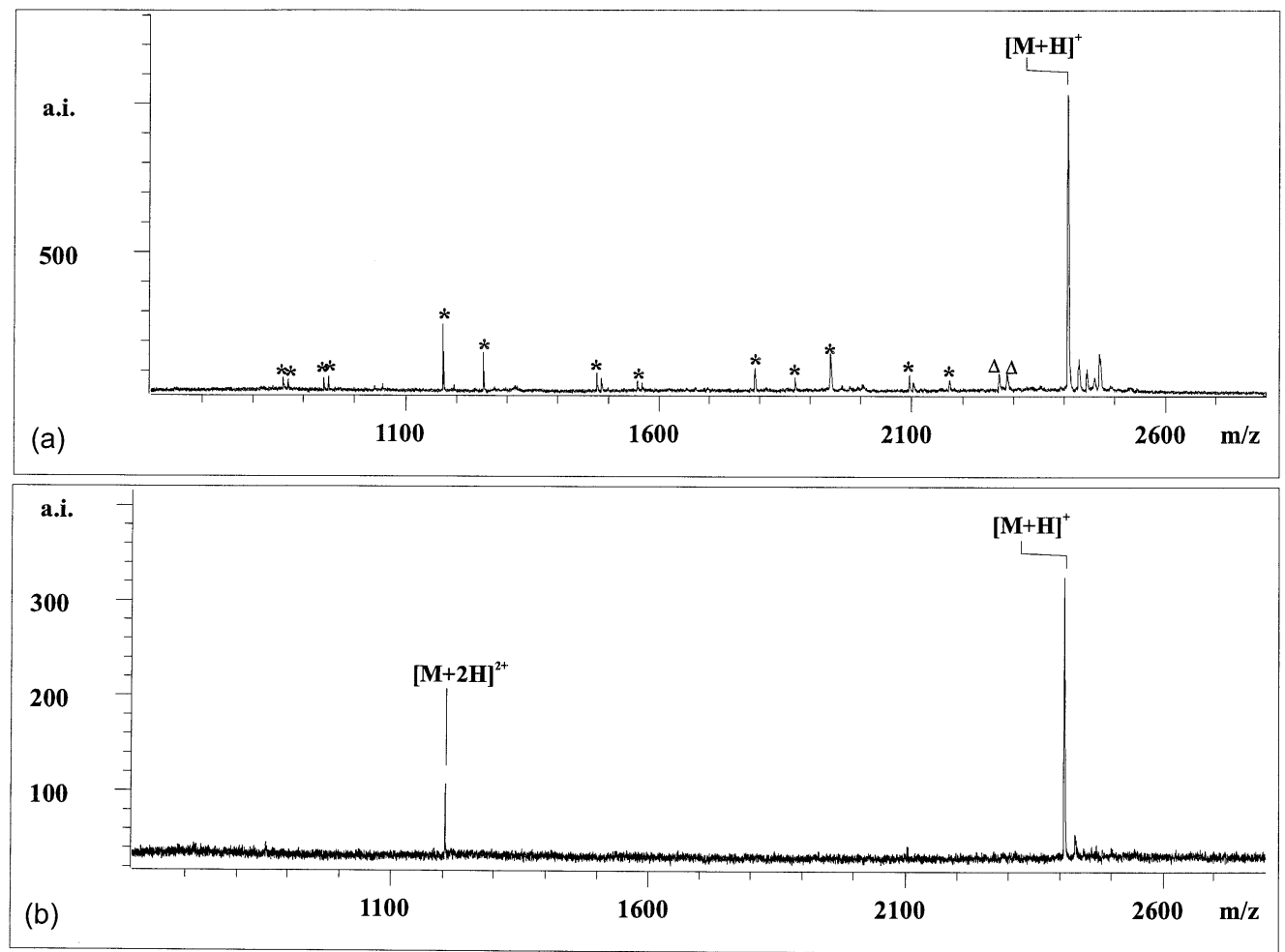

Figure 2. Positive-ion reflectron time-of-flight mass spectra of d(TATATATA) using (a) ABA/ $\mathrm{NH}_{4} \mathrm{~F}$ and (b) $\mathrm{HPA} / \mathrm{NH}_{4} \mathrm{~F}$ matrices. Both spectra were obtained at the same laser fluence. Peaks marked with an asterisk and a triangle are fragment ions derived from fast and metastable dissociations of d(TATATATA) molecule-ions, respectively.

d(TATATATA) molecule-ions. It was interesting noted that peaks marked with triangles could not readily be correlated with any reasonable fragments. It is wellknown that metastable ions with masses close to the precursor ion can sometimes be reflected to the detector and be recorded at the "wrong masses" under normal reflectron settings. To distinguish prompt fragment ions from the metastable ions, the linear time-of-flight mass spectra for the corresponding oligonucleotides were also measured. Figure 3 shows portions of the linear, reflectron and post-source-decay mass spectra of d(TATATATA). By direct comparison of the linear and reflectron time-of-flight mass spectra, the fragment peaks at $\mathrm{m} / \mathrm{z} 2272.5$ and $\mathrm{m} / \mathrm{z} 2287.0$ can therefore be attributed to the metastable dissociation of the precursor ions. The identities of these peaks were confirmed from the corresponding PSD spectrum to be $[\mathrm{M}-\mathrm{AH}]^{+}$ and $\left[\mathrm{M}-\mathrm{AH}-\mathrm{H}_{2} \mathrm{O}\right]^{+}$, respectively (see Figure $3 \mathrm{c}$ ).

Figure 4 shows the positive-ion reflectron time-offlight mass spectra of $\mathrm{pd}(\mathrm{AT})_{4}, \mathrm{~d}(\mathrm{AT})_{4}$ and $\mathrm{d}(\mathrm{AT})_{4} \mathrm{p}$. The spectral information is summarized in Table 3 for comparison. Using $\mathrm{ABA} / \mathrm{NH}_{4} \mathrm{~F}$ matrix, fast fragmentation of oligonucleotides was found to differ from the corresponding metastable dissociation in which the liability of nucleobase does not seem to exert any significant effect on the site of backbone cleavage. Series of $\mathrm{b}_{\mathrm{n}}^{+}, \mathrm{d}_{\mathrm{n}}^{+}, \mathrm{w}_{\mathrm{n}}^{+}$and $\mathrm{y}_{\mathrm{n}}^{+}$ions were produced, where $\mathrm{n}$ is an integer from 2 to 7 . It is also worthwhile to point out that ion series of $\mathrm{w}_{\mathrm{n}}^{+}, \mathrm{b}_{\mathrm{n}}^{+}, \mathrm{y}_{\mathrm{n}}^{+}$and $\mathrm{d}_{\mathrm{n}}^{+}$were generated from the cleavage of different backbone linkages, i.e., 5'-CO, 5'-PO, 3'-PO and 3'-CO, respectively. No complimentary ion series were found. Similar fast fragmentation pattern has also been reported when 2,4,6-trihydroxyacetophenone/ammonium citrate $[19,20]$ and 2-amino-5-nitropyridine/ammonium fluoride [12] were used as matrices under UV laser desorption conditions.

Another interesting finding is that the presence of additional phosphate at either $3^{\prime}$ or 5'-terminal would significantly influence the fragmentation pattern of oligonucleotides tested. As compare with d(TATATATA), the 5'-phosphylated species, i.e., pd(TATATATA), fragmented preferentially to form b-ions with little or no d-ions (see Table 4). On the contrary, the 3'-phosphylated species, i.e., d(TATATATA)p, fragmented mainly to form d-ions but not b-ions. In addition, it was noted that 5'-phosphylated oligonucleotides would undergo substantial loss of neutral $\mathrm{HPO}_{3}$ to form abundant $[\mathrm{M}-\mathrm{P}]^{+}$ions. This fragment ion was found to cleave consecutively or concertedly to form a series of $\left[b_{n}-P\right]^{+}$. The $\left[b_{3}-\mathrm{P}\right]^{+},\left[b_{5}-\mathrm{P}\right]^{+}$and $\left[b_{7}-\mathrm{P}\right]^{+}$ions were observed at $\mathrm{m} / \mathrm{z}$ 860.1, 1477.3 and 2094.6, respectively. Other members of the $\left[b_{n}-P\right]^{+}$ions were however found to be redundant in masses with $\mathrm{y}_{\mathrm{n}}^{+}$ions, such as $\left[\mathrm{b}_{2}-\mathrm{P}\right]^{+} / \mathrm{y}_{2}$; $\left[b_{4}-\mathrm{P}\right]^{+} / \mathrm{y}_{4} ;\left[\mathrm{b}_{6}-\mathrm{P}\right]^{+} / \mathrm{y}_{6}$ ions. Other series of fragment ions, such as $\mathrm{w}_{\mathrm{n}}^{+}$and $\mathrm{y}_{\mathrm{n}}^{+}$, did not produce similar ions. Loss of neutral $\mathrm{HPO}_{3}$ was however not found in any 


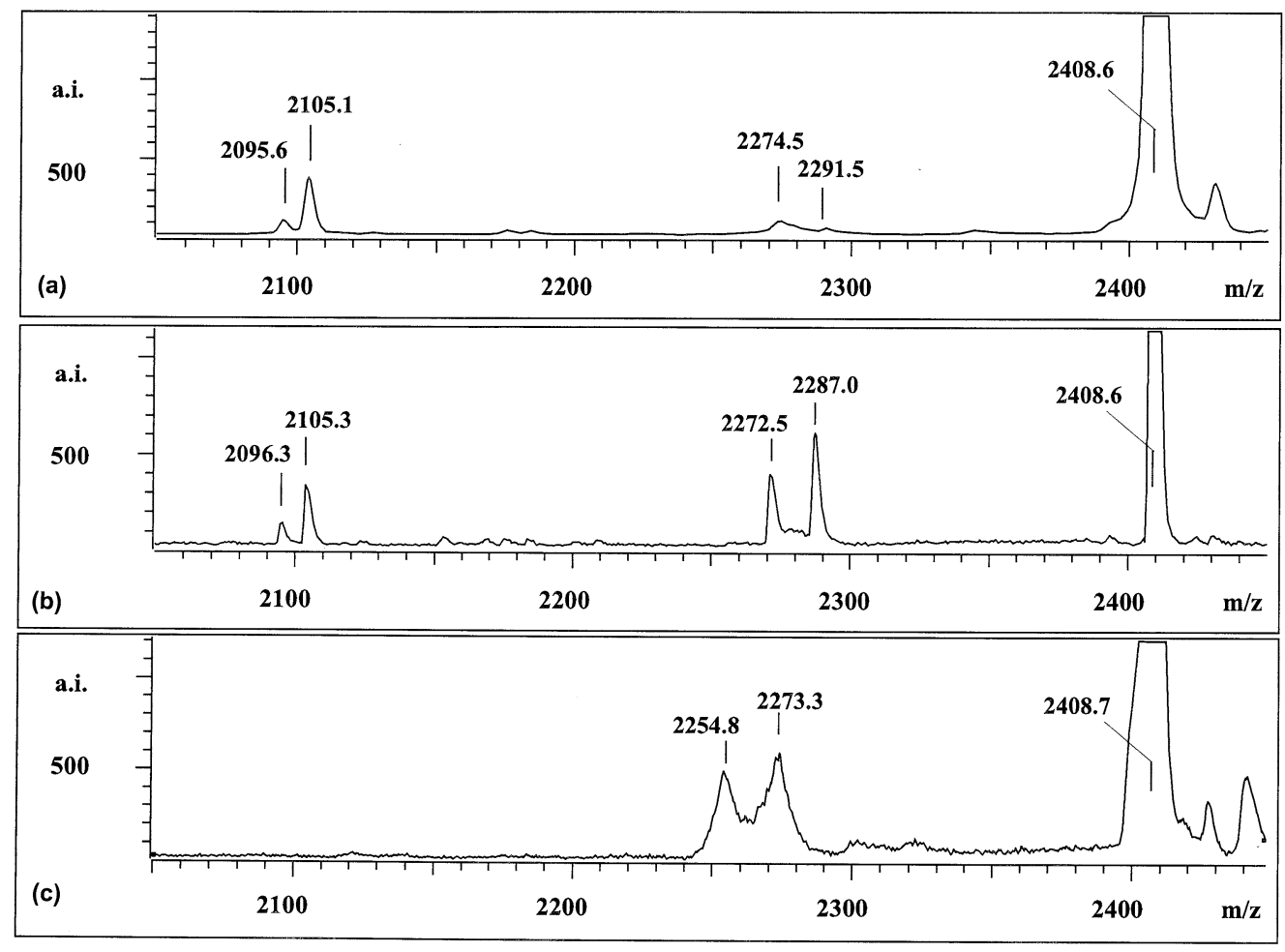

Figure 3. Portions of (a) linear, (b) reflectron, and (c) post-source decay mass spectra of d(TATATATA).
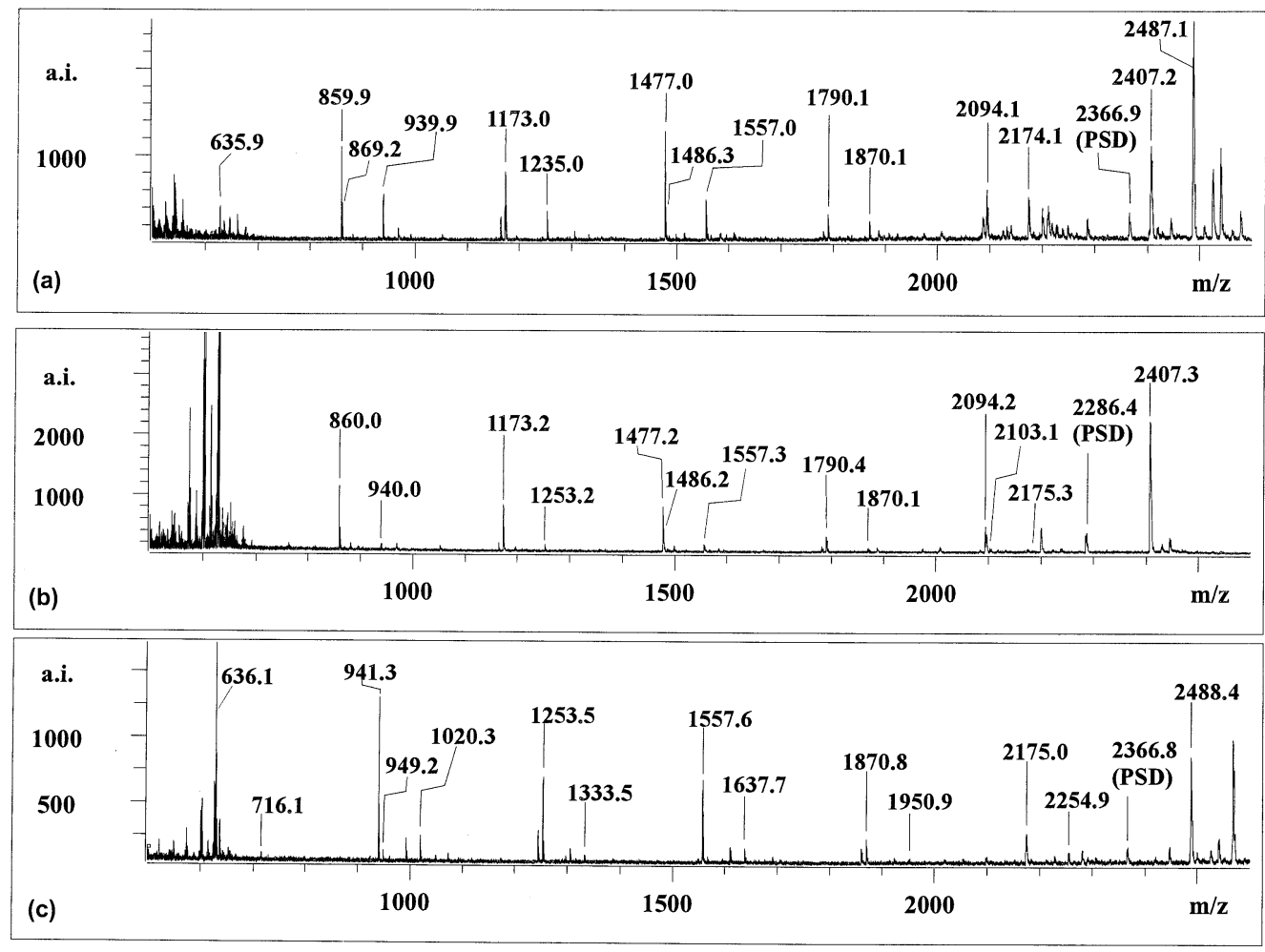

Figure 4. Positive-ion reflectron time-of-flight mass spectra of (a) $\operatorname{pd}(\operatorname{ATATATAT})$; (b) d(ATATATAT); and (c) d(ATATATAT)p using ABA/ $\mathrm{NH}_{4} \mathrm{~F}$ matrix. 
Table 3. Summary of positive-ion MALDI mass spectra of pd(ATATATAT), d(ATATATAT) and d(ATATATAT)p by using ABA/ $\mathrm{NH}_{4} \mathrm{~F}$ matrix ${ }^{\mathrm{a}}$

\begin{tabular}{|c|c|c|c|c|c|c|c|c|c|c|c|c|}
\hline & \multicolumn{4}{|c|}{$\operatorname{pd}($ ATATATA) } & \multicolumn{4}{|c|}{$\mathrm{d}($ ATATATAT) } & \multicolumn{4}{|c|}{$d($ ATATATAT)p } \\
\hline & Calculated & Measured & $\Delta \mathrm{m}$ & r.i. & Calculated & Measured & $\Delta \mathrm{m}$ & r.i. & Calculated & Measured & $\mathrm{d} \Delta \mathrm{m}$ & r.i. \\
\hline $\mathrm{M}^{+}$ & 2487.4 & 2487.1 & 0.3 & 1.00 & 2407.5 & 2407.3 & 0.2 & 1.00 & $2488.7^{b}$ & $2488.4^{b}$ & 0.3 & 1.00 \\
\hline$[\mathrm{M}-\mathrm{P}]^{+}$ & 2407.4 & 2407.2 & 0.2 & 0.50 & & ND & - & - & & ND & - & - \\
\hline$[\mathrm{M}-\mathrm{AH}]^{+}(\mathrm{PSD}$ peak) & 2352.3 & 2366.9 & NA & 0.16 & 2273.6 & 2286.4 & NA & 0.18 & 2352.3 & 2366.8 & NA & 0.18 \\
\hline $\mathrm{w}_{7}^{+}$ & 2174.4 & 2174.1 & 0.3 & 0.25 & $2175.5^{b}$ & $2175.3^{b}$ & 0.2 & 0.07 & 2254.4 & 2254.9 & 0.5 & 0.16 \\
\hline$y_{7}^{+}$ & 2094.4 & 2094.1 & 0.3 & 0.27 & 2094.4 & 2094.2 & 0.2 & 0.22 & 2174.4 & 2175.0 & 0.6 & 0.33 \\
\hline $\mathrm{b}_{7}^{+}$ & & ND & - & - & 2103.4 & 2103.1 & 0.3 & 0.08 & & ND & - & - \\
\hline $\mathrm{w}_{6}{ }^{+}{ }^{\mathrm{c}}\left(\mathrm{b}_{6}{ }^{+} /\left[\mathrm{d}_{6}-\mathrm{P}\right]^{+} /\left[\mathrm{w}_{6}-\mathrm{P}\right]^{+}\right)^{\mathrm{d}}\left(\mathrm{d}_{6}{ }^{+}\right)$ & 1870.3 & 1870.1 & 0.2 & 0.13 & 1870.3 & 1870.1 & 0.2 & 0.06 & 1950.3 & 1950.8 & 0.5 & 0.09 \\
\hline $\begin{array}{l}\mathrm{y}_{6}^{+}{ }^{+c}\left(\left[b_{6}-P\right]^{+} /\left[y_{6}-P\right]^{+}\right)^{d}\left(b_{6}^{+}\right) \\
{ }^{e}\left(d_{6}^{+}\right)\end{array}$ & 1790.4 & 1790.1 & 0.3 & 0.16 & 1790.4 & 1790.2 & 0.2 & 0.15 & 1870.3 & 1870.8 & 0.5 & 0.27 \\
\hline $\mathrm{w}_{5}^{+}$ & 1557.3 & 1557.0 & 0.3 & 0.23 & 1557.3 & 1557.1 & 0.2 & 0.10 & 1637.2 & 1637.7 & 0.5 & 0.19 \\
\hline$y_{5}^{+}$ & 1477.3 & 1477.0 & 0.3 & 0.60 & 1477.3 & 1477.2 & 0.1 & 0.42 & 1557.3 & 1557.6 & 0.3 & 0.79 \\
\hline$b_{5}^{+}$ & 1486.3 & 1486.3 & 0.0 & 0.04 & 1486.3 & 1486.2 & 0.1 & 0.06 & & ND & - & - \\
\hline $\mathrm{w}_{4}{ }^{+}{ }^{\mathrm{c}}\left(\mathrm{b}_{4}{ }^{+} /\left[\mathrm{d}_{4}-\mathrm{P}\right]^{+} /\left[\mathrm{w}_{4}-\mathrm{P}\right]^{+}\right){ }^{\mathrm{d}}\left(\mathrm{d}_{4}{ }^{+}\right)$ & 1253.2 & 1253.0 & 0.2 & 0.17 & 1253.2 & 1253.2 & 0.0 & 0.10 & 1333.2 & 1333.5 & 0.3 & 0.12 \\
\hline $\begin{array}{l}\mathrm{y}_{4}^{+}{ }^{+} \mathrm{c}\left(\left[\mathrm{b}_{4}-\mathrm{P}\right]^{+} /\left[\mathrm{y}_{4}-\mathrm{P}\right]^{+}\right)^{\mathrm{d}}\left(\mathrm{b}_{4}^{+}\right) \\
\left.\mathrm{d}_{4}^{+}\right)\end{array}$ & 1173.3 & 1173.0 & 0.3 & 0.38 & 1173.3 & 1173.2 & 0.1 & 0.43 & 1253.2 & 1253.5 & 0.3 & 0.81 \\
\hline $\mathrm{w}_{3}^{+}$ & 940.2 & 939.9 & 0.3 & 0.26 & 940.2 & 940.0 & 0.2 & 0.09 & 1020.1 & 1020.3 & 0.2 & 0.29 \\
\hline $\mathrm{y}_{3}^{+}$ & 860.2 & 859.9 & 0.3 & 0.51 & 860.2 & 860.0 & 0.2 & 0.58 & $940.6^{b}$ & $941.3^{b}$ & 0.7 & 1.53 \\
\hline $\mathrm{d}_{3}^{+}$ & & ND & - & - & & ND & - & - & 949.2 & 949.2 & 0.0 & 0.16 \\
\hline $\mathrm{b}_{3}^{+}$ & 869.2 & 869.2 & 0.0 & 0.03 & & ND & - & - & & ND & - & - \\
\hline $\mathrm{w}_{2}{ }^{+\mathrm{c}}\left(\mathrm{b}_{2}{ }^{+} /\left[\mathrm{d}_{2}-\mathrm{P}\right]^{+} /\left[\mathrm{w}_{2}-\mathrm{P}\right]^{+}\right)$ & 636.1 & 635.8 & 0.3 & 0.12 & & ND & - & - & 716.1 & 716.1 & 0.0 & 0.14 \\
\hline $\mathrm{y}_{2}+\mathrm{e}\left(\mathrm{d}_{2}{ }^{+}\right)$ & & ND & - & - & & ND & - & - & 636.1 & 636.1 & 0.0 & 0.42 \\
\hline
\end{tabular}

aunless specifically stated, all data are calculated and measured with mono-isotopic masses;

${ }^{\mathrm{b}}$ data are calculated or measured with average masses;

capply only to pd(ATATATAT);

dapply only to d(ATATATAT);

eapply only to d(ATATATAT)p $\% \mathrm{ND}=$ not detected $\% \mathrm{NA}=$ not applicable $\%$ r.i. = relative intensity with respect to the molecular ions

significant extent for 3'-phosphylated oligonucleotides. Although the origin of the preferential loss of neutral $\mathrm{HPO}_{3}$ from 5'-phosphylated oligonucleotides is not known, the present findings provided a convenient way of differentiating 5 ' and $3^{\prime}$-phosphylated isomers.

The formation of $b_{n}^{+}, d_{n}^{+}, w_{n}^{+}$and $y_{n}^{+}$product ions (without their complimentary ions) under standard reflectron time-of-flight conditions was intriguing. Their formation could be attributed to the desorption/ ionization of the hydrolysis products of the original oligonucleotides. The hydrolysis reaction could take place in solution during the mixing of the oligonucleotide and ABA solutions or be induced in solid state after laser irradiation. The solution-phase acid catalyzed hydrolysis of oligonucleotide molecules was precluded by the relatively high $\mathrm{pH}$ of the ABA solution $(\mathrm{pH}=3.9)$ in comparison with that of the HPA solution (i.e., $\mathrm{pH}=$ 3.6). Being a more acidic matrix, HPA has induced no observable hydrolysis products (see Figure $2 b$ ). From a separate experiment using trifluoroacetic acid (TFA) as acidifying agent, it was found that low $\mathrm{pH}$ could only induce hydrolysis of the labile bases with no observable backbone hydrolysis (data not shown). Although the possibility of laser-induced solid-state hydrolysis of the oligonucleotides cannot completely be precluded, the preferential formation of $[\mathrm{M}-\mathrm{P}]^{+}, \mathrm{b}_{\mathrm{n}}^{+}$and $\left[\mathrm{b}_{\mathrm{n}}-\mathrm{P}\right]^{+}$ions by 5'-phospylated oligonucleotides; and $\mathrm{d}_{\mathrm{n}}^{+}$ions by 3'phosphylated oligonucleotides do support a more specific fragmentation mechanism. With the present exper- imental results, it was however rather speculative to rationalize our observations with any dissociation mechanisms.

\section{Fast vs. Metastable Dissociation}

Factors governing the fragmentation pattern of oligonucleotides in mass spectrometry are of both fundamental and practical interest. More related information would allow a better control of the degree of fragmentation, which is particularly important for characterization of natural and modified oligonucleotides. An improved theoretical understanding of the fragmentation of oligonucleotides can also underpin more securely the interpretation of the mass spectrum for this class of biomolecules. In this section, we attempt to correlate our observations with the results previously reported in the literatures and to propose a model of precursor ion activation under MALDI conditions without going into detailed mechanisms of ion fragmentation.

Numerous dissociation pathways exist in large polyatomic ions, such as oligonucleotides. The fragmentation pattern observation under a particular time-window (fast or PSD) is the result of a set of competitive and consecutive cleavages of the precursor ions provided that the internal energy of the precursor ions exceeds the critical energies for such cleavages. Figure 5 shows a hypothetical relationship of $P(\mathrm{E})$ and $\ln k(\mathrm{E})$ for ion decomposition of a precursor ion $\mathrm{M}^{+}$, where $\mathrm{E}$ is the 


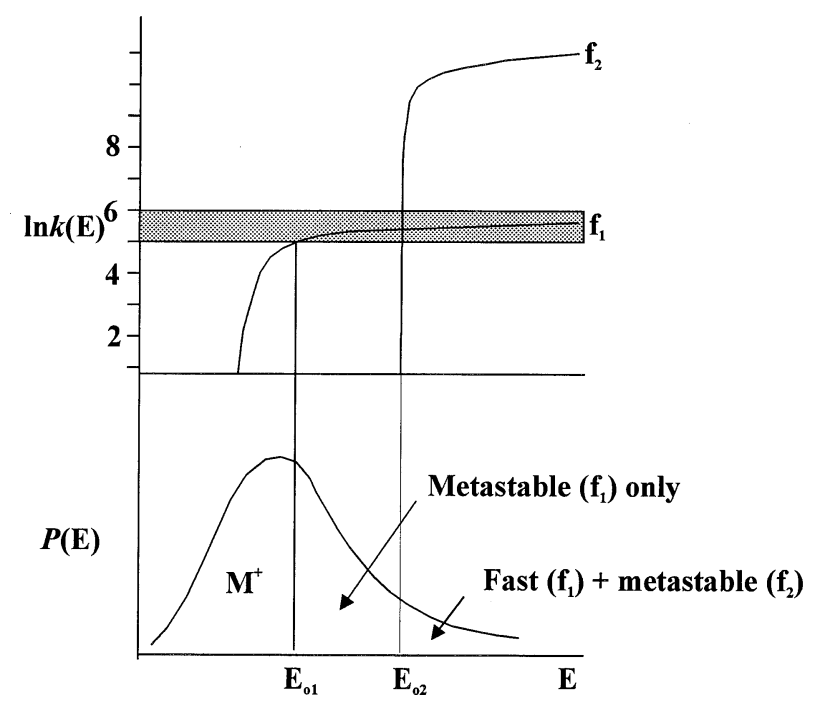

Figure 5. A Warhaftig diagram for the decomposition of a precursor ion $\mathrm{M}^{+}$, where $\mathrm{E}$ is the internal energy of $\mathrm{M}^{+}, P(\mathrm{E})$ is the probability function and $k(\mathrm{E})$ is the dissociation rate constant. $\mathrm{E}_{\mathrm{o} 1}$ and $\mathrm{E}_{\mathrm{o} 2}$ correspond to the critical energies for dissociation of the precursor ion $\mathrm{M}^{+}$into Fragment $1\left(f_{1}\right)$ and Fragment $2\left(f_{2}\right)$, respectively.

internal energy of $\mathrm{M}^{+}, P(\mathrm{E})$ is the probability function and $k(\mathrm{E})$ is the rate constant for dissociation. Suppose $E_{\mathrm{o} 1}$ and $\mathrm{E}_{\mathrm{o} 2}$ correspond to the critical energies for dissociation of precursor ions $\left(\mathrm{M}^{+}\right)$into $f_{1}$ and $f_{2}$, respectively. The internal energy distribution of the precursor ions can be represented by curve as shown in Figure 5 (top). For portion of $\mathrm{M}^{+}$with internal energy (E) lower than the lowest critical energy for dissociation, i.e., $\mathrm{E}_{\mathrm{o} 1}$, the $\mathrm{M}^{+}$would remain intact with time. For portion of $\mathrm{M}^{+}$with internal energy higher than $\mathrm{E}_{\mathrm{o} 1}$, the $\mathrm{M}^{+}$would have sufficient energy to undergo dissociation into $f_{1}$. However, the rate of dissociation $(k)$ depends on the excess energy, i.e.. $\left(\mathrm{E}-\mathrm{E}_{\mathrm{o} 1}\right)$. If the rate is too slow $(\ln (k)<5)$, the $\mathrm{M}^{+}$might not fragment before passing through the mass analyzer and be detected as intact $\mathrm{M}^{+}$. If the rate is sufficient fast $(\ln (k)>6)$, the $\mathrm{M}^{+}$ would fragment into $f_{1}$ in the ion source prior to ion extraction and be detected as prompt fragment. For those precursor ions with internal energies in which the rate is some what in between $(\ln (k) \sim 5-6)$, the $\mathrm{M}^{+}$ would fragment in the field free region of the mass spectrometer and be detected as metastable ions. For portion of $\mathrm{M}^{+}$with internal energy higher than $\mathrm{E}_{\mathrm{o} 2}$, formation of $f_{2}$ becomes in competitive with the formation of $f_{1}$. Again, the $f_{2}$ might be detected as metastable ions or prompt ions depending on the excess energy and hence the rate of dissociation.

In general, formation of the same set of fragments from the same precursor ions at different time-windows can be attributed to the difference in the internal energy of the precursor ions. Fragment ions observed in fast dissociaiton conditions are generated from precursor ions of higher internal energy as compare to those observed in PSD conditions. From the recent blackbody infrared irradiative dissociation (BIRD) studies [26] and the numerous post-source decay analysis $[29,30]$, it has been confirmed that the loss of labile nucleobase $[\mathrm{M}-\mathrm{B}]^{+}$ and the subsequent formation of $\left[\mathrm{a}_{\mathrm{n}}-\mathrm{B}\right]^{+}, \mathrm{w}_{\mathrm{n}}^{+},\left[\mathrm{z}_{\mathrm{n}}-\mathrm{B}\right]^{+}$ and $\mathrm{d}_{\mathrm{n}}^{+}$ions proceed via the lowest energy dissociation pathways (i.e., $f_{2}$ ). Alternatively, formation of $b_{n}^{+}, d_{n}^{+}$, $\mathrm{w}_{\mathrm{n}}^{+}$and $\mathrm{y}_{\mathrm{n}}^{+}$ion series must be proceeded via some higher energy dissociation pathways (i.e., $f_{1}$ ) or via some specific matrix-directed decomposition pathways.

One of the important findings in the present study is the mutually exclusive occurrence of the two sets of fragment ions in fast and metastable conditions under UV-MALDI conditions using $\mathrm{ABA} / \mathrm{NH}_{4} \mathrm{~F}$ matrix. This observation might not seem extraordinary by assuming that their fragmentation pathways require rather different critical energies. As long as the rate of formation of $f_{1}$ (i.e., $[\mathrm{M}-\mathrm{B}]^{+},\left[\mathrm{a}_{\mathrm{n}}-\mathrm{B}\right]^{+} / \mathrm{w}_{\mathrm{n}}^{+}$) from the precursor ions $\mathrm{M}^{+}$ is sufficient low $(\ln k[\mathrm{E}]<6)$ even for $\mathrm{M}^{+}$with internal energy sufficient high to form $f_{2}$ (i.e., $\mathrm{y}_{\mathrm{n}}^{+}$), $f_{1}$ and $f_{2}$ ions might exclusively exist in the PSD or prompt spectrum, respectively. However, if we include fragmentation pattern reported previously in literature [31,32] by using 2,5-dihydroxybenzoic acid (DHB) as matrix (UVMALDI), such a simple explanation might become insufficient. By using DHB as matrix, the fragmentation pathways of oligonucleotides under prompt conditions were found to resemble those of the metastable dissociation, i.e. formation of $[\mathrm{M}-\mathrm{B}]^{+}$and $\left[\mathrm{a}_{\mathrm{n}}-\mathrm{B}\right]^{+} / \mathrm{w}_{\mathrm{n}}^{+}$. This implies that the rate of formation of $f_{1}$ from $\mathrm{M}^{+}$could be fast enough to appear in the prompt spectrum if the internal energy of $\mathrm{M}^{+}$is large enough. This would therefore seem to contradict with our observations that no $f_{1}$ (i.e., $[\mathrm{M}-\mathrm{B}]^{+}$and $\left[\mathrm{a}_{\mathrm{n}}-\mathrm{b}\right]^{+} / \mathrm{w}_{\mathrm{n}}^{+}$) was found in prompt spectra even though abundant $f_{2}$ (i.e., $\mathrm{y}_{\mathrm{n}}^{+}$) were observed. One might suggest that the $f_{1}$ observed in prompt spectra were originated from the subsequent dissociation of $f_{1}$ rather from the precursor ions under MALDI conditions using $\mathrm{ABA} / \mathrm{NH}_{4} \mathrm{~F}$ as matrix. The main objection to this hypothesis is that $f_{1}$ were not found even at threshold laser irradiance for production of the precursor ions, whereas significant $f_{2}$ signals were already exist. The high stability of $f_{1}$ formed from precursor ions of high internal energy can actually be deduced from the DHB experiments.

In attempts to explain our observations, we propose a model of precursor ion activation under UV-MALDI conditions. It is generally believed that the matrix molecules play a critical role in absorbing the laser photons and distributing the energy in such a way that the embedded analyte molecules would be desorbed and ionized with minimum internal energy. Different models have been proposed [33-36] to explain the desorption and ionization phenomena under UVMALDI conditions. In general, it is believed that some sorts of bottleneck [37] exist in the transfer of internal energy from the highly excited matrix moieties to the analyte ions. Nevertheless, excitation of the analyte ions does occur. We tentatively propose that there might be, at least, two possible modes of energy transfer from the 
Table 4. Summary of positive-ion MALDI mass spectra of pd(TATATATA), d(TATATATA) and d(TATATATA)p by using ABA/ $\mathrm{NH}_{4} \mathrm{~F}$ matrix ${ }^{\mathrm{a}}$

\begin{tabular}{|c|c|c|c|c|c|c|c|c|c|c|c|c|}
\hline & \multicolumn{4}{|c|}{ pdTATATATA) } & \multicolumn{4}{|c|}{ d(TATATATA) } & \multicolumn{4}{|c|}{$\mathrm{d}($ TATATATA $) \mathrm{p}$} \\
\hline & Calculated & Measured & $\Delta \mathrm{m}$ & r.i. & Calculated & Measured & $\Delta \mathrm{m}$ & r.i. & Calculated & Measured & $\Delta \mathrm{m}$ & r.i. \\
\hline $\mathrm{M}^{+}$ & 2487.4 & 2487.7 & 0.3 & 1.00 & $2408.7^{b}$ & $2409.4^{b}$ & 0.7 & 1.00 & $2488.7^{b}$ & $2487.5^{b}$ & 0.7 & 1.00 \\
\hline$[\mathrm{M}-\mathrm{P}]^{+}$ & $2407.4^{b}$ & 2407.6 & 0.2 & 1.34 & & ND & - & - & & ND & - & - \\
\hline$[\mathrm{M}-\mathrm{AH}]^{+}(\mathrm{PSD}$ peak) & $2353.6^{b}$ & $2368.1^{b}$ & NA & 0.18 & $2273.6^{b}$ & $2288.0^{\mathrm{b}}$ & NA & 0.15 & $2353.6^{b}$ & $2369.3^{\mathrm{b}} \mathrm{N}$ & VA & 0.13 \\
\hline$\left[\mathrm{M}-\mathrm{AH}-\mathrm{H}_{2} \mathrm{O}\right]^{+}(\mathrm{PSD}$ peak) & & ND & - & - & $2255.6^{b}$ & $2272.6^{\mathrm{b}}$ & NA & 0.13 & & ND & - & - \\
\hline$w_{7}^{+}$ & $2184.5^{b}$ & $2184.4^{b}$ & 0.1 & 0.13 & & ND & - & - & & ND & - & - \\
\hline$y_{7}^{+}$ & 2103.4 & 2103.4 & 0.0 & 0.20 & $2104.5^{b}$ & $2104.8^{b}$ & 0.3 & 0.02 & $2184.5^{b}$ & $2184.4^{b}$ & 0.1 & 0.09 \\
\hline $\mathrm{d}_{7}^{+}$ & & ND & - & - & $2175.5^{b}$ & $2175.7^{b}$ & 0.2 & 0.04 & $2175.5^{b}$ & $2176.4^{b}$ & 0.9 & 0.06 \\
\hline $\mathrm{b}_{7}^{+}$ & $2175.5^{b}$ & $2175.5^{b}$ & 0.0 & 0.09 & $2095.5^{b}$ & $2095.6^{b}$ & 0.1 & 0.05 & & ND & - & - \\
\hline$\left[\mathrm{b}_{7}-\mathrm{P}\right]^{+}$ & 2094.4 & 2094.6 & 0.2 & 0.10 & & ND & - & - & & ND & - & - \\
\hline$\left[b_{7}-\mathrm{AH}+\mathrm{OH}\right]^{+}$ & & ND & - & - & $1977.4^{b}$ & $1978.1^{\mathrm{b}}$ & 0.7 & 0.005 & & ND & - & - \\
\hline$w_{6}{ }^{+c}\left(b_{6}{ }^{+} /\left[d_{6}-P\right]^{+} /\left[w_{6}-P\right]^{+}\right){ }^{d}\left(d_{6}{ }^{+}\right)$ & 1870.3 & 1870.4 & 0.1 & 0.14 & $1871.3^{b}$ & $1871.5^{b}$ & 0.2 & 0.02 & 1950.3 & 1950.7 & 0.4 & 0.07 \\
\hline $\mathrm{y}_{6}{ }^{+c}\left(\left[\mathrm{~b}_{6}-\mathrm{P}\right]^{+} /\left[\mathrm{y}_{6}-\mathrm{P}\right]^{+}\right)^{\mathrm{d}}\left(\mathrm{b}_{6}{ }^{+}\right)$ & 1790.4 & 1790.4 & 0.0 & 0.27 & $1791.3^{b}$ & $1791.4^{b}$ & 0.1 & 0.04 & 1870.3 & 1870.7 & 0.4 & 0.14 \\
\hline$w_{5}^{+}$ & 1566.3 & 1566.3 & 0.0 & 0.10 & 1566.3 & 1566.6 & 0.3 & 0.01 & & ND & - & - \\
\hline$y_{5}^{+}$ & 1486.3 & 1486.3 & 0.0 & 0.31 & 1486.3 & 1486.6 & 0.2 & 0.02 & $1567.1^{b}$ & $1567.5^{\mathrm{b}}$ & 0.4 & 0.11 \\
\hline$d_{5}{ }^{+}$ & & ND & - & - & 1557.3 & 1557.5 & 0.2 & 0.01 & 1557.3 & 1557.5 & 0.2 & 0.13 \\
\hline$b_{5}^{+}$ & 1557.3 & 1557.3 & 0.0 & 0.07 & 1477.3 & 1477.5 & 0.7 & 0.02 & & ND & - & - \\
\hline$\left[b_{5}-P\right]^{+}$ & 1477.3 & 1477.3 & 0.0 & 0.10 & & ND & - & - & & ND & - & - \\
\hline$w_{4}^{+}{ }^{c}\left(b_{4}^{+} /\left[d_{4}-P\right)^{+} /\left[w_{4}-P\right]^{+}\right)^{d}\left(d_{4}^{+}\right)$ & 1253.2 & 1253.2 & 0.0 & 0.32 & 1253.2 & 1253.4 & 0.2 & 0.02 & 1333.2 & 1333.3 & 0.1 & 0.14 \\
\hline $\mathrm{y}_{4}{ }^{+\mathrm{c}}\left(\left[\mathrm{b}_{4}-\mathrm{P}\right]^{+} /\left[\mathrm{y}_{4}-\mathrm{P}\right]^{+}\right)^{\mathrm{d}}\left(\mathrm{b}_{4}{ }^{+}\right)^{\mathrm{e}}\left(\mathrm{d}_{4}{ }^{+}\right)$ & 1173.3 & 1173.2 & 0.1 & 0.92 & 1173.3 & 1173.4 & 0.1 & 0.02 & 1253.2 & 1253.3 & 0.1 & 0.69 \\
\hline$\left[\mathrm{d}_{4} / \mathrm{w}_{4}-\mathrm{AH}+\mathrm{OH}-\mathrm{H}_{2} \mathrm{O}\right]^{+}$ & & ND & - & - & 1117.7 & $1118.2^{\mathrm{b}}$ & 0.5 & 0.01 & & ND & - & - \\
\hline $\mathrm{w}_{3}^{+}$ & 949.2 & 949.1 & 0.1 & 0.16 & 949.2 & 949.1 & 0.1 & 0.01 & 716.1 & 715.9 & 0.2 & 0.19 \\
\hline$y_{3}{ }^{+}$ & 869.2 & 869.1 & 0.1 & 0.47 & & ND & - & - & 949.2 & 949.1 & 0.1 & 0.35 \\
\hline $\mathrm{d}_{3}^{+}$ & & ND & - & - & 940.2 & 940.1 & 0.1 & 0.01 & 940.2 & 940.1 & 0.1 & 0.13 \\
\hline $\mathrm{b}_{3}^{+}$ & 940.2 & 940.1 & 0.1 & 0.12 & & ND & - & - & & ND & - & - \\
\hline$\left[b_{3}-P\right]^{+}$ & 860.2 & 860.1 & 0.1 & 0.26 & & ND & - & - & & ND & - & - \\
\hline $\mathrm{w}_{2}{ }^{+\mathrm{c}}\left(\mathrm{b}_{2}{ }^{+} /\left[\mathrm{d}_{2}-\mathrm{P}\right]^{+} /\left[\mathrm{w}_{2}-\mathrm{P}\right]^{+}\right)$ & 636.1 & 636.0 & 0.1 & 0.29 & & ND & - & - & & ND & - & - \\
\hline $\mathrm{y}_{2}{ }^{+c}\left(\left[\mathrm{~b}_{2}-\mathrm{P}\right]^{+} /\left[\mathrm{y}_{2}-\mathrm{P}\right]^{+}\right)$ & 556.2 & 556.1 & 0.1 & 0.47 & & ND & - & - & & ND & - & - \\
\hline
\end{tabular}

aunless specifically stated, all data are calculated and measured with mono-isotopic masses.

${ }^{b}$ data are calculated or measured with average masses

capply to pd(TATATATA) only.

dapply to d(TATATATA) only.

eapply to d(TATATATA)p only. $\% \mathrm{ND}=$ not detected; $\mathrm{NA}=$ not applicable; r.i. = relative intensity with respect to the molecular ions

excited matrix moieties to the co-desorbed analyte ions. One energy-transfer mode might involve thermal excitation of the analyte ions. It is known that absorption of UV-photons by the matrix molecules would lead to electronic excitation and very likely accomplished with a substantial vibrational excitation. The fast internal conversion process would dissipate the excess vibrational energy to the surrounding particles as heat (i.e., thermal excitation). Analyte ions excited by this thermal energy would have a distribution of internal energy. Depending on the matrix molecules and the laser irradiance, analyte ions would be excited to different extents. Matrix molecules/ions, such as HPA, ABA and ANP, would liberate small amount of thermal energy after laser excitation and would induce predominantly metastable dissociation of the oligonucleotide ions. The metastable dissociation pathways of oligonucleotides under these conditions would therefore resemble to those induced by IR-MALDI and BIRD techniques. Using other matrices, such as DHB, or at higher laser fluence, the analyte ions would acquire larger amount of thermal energy and undergo fast dissociation. Nevertheless, the dissociation pathway remains the same. Another energy-transfer mode might involve specific matrix-analyte coupling at electronic level. Since the quanta of energy transferred are in electronic level, a rather different set of dissociation pathways could be induced, such as $\mathrm{d}_{\mathrm{n}}^{+}, \mathrm{b}_{\mathrm{n}}^{+}, \mathrm{w}_{\mathrm{n}}^{+}$and $\mathrm{y}_{\mathrm{n}}^{+}$. Since the critical energy for this set of dissociation pathways is much higher (i.e., electronic excitation), the resulted fragments would not be observed by using other thermal excitation techniques. It is however important to stress that our hypothesis is based on the sole consideration of the internal energy of the precursor ions, the occurrence of the mutually exclusive product ions and the timescales of fast and metastable dissociations. With the limited experimental results (especially on fast dissociation of oligonucelotides), other reasonable hypotheses cannot be excluded.

\section{Conclusions}

We have analyzed the fast and metastable dissociation products of a series of adenine-thymine binary-base oligonucleotides using UV matrix-assisted laser desorption/ionization mass spectrometry. Using the same matrix system, these oligonucleotides generated two different sets of dissociation products under fast and 
metastable dissociation conditions. Together with some literature findings, it is postulated that the activated matrix molecules/ions could transfer energy to the embedded analyte molecules via (at least) two energy transfer modes, i.e., thermal and electronic energy transfer. The relative importance of these energy transfer channels depends critically on the nature of the matrix molecules and the matrix-analyte interactions (Table 4).

\section{References}

1. Pieles, U.; Zürcher, W.; Schar, M.; Moser, H.Z. Matrix-Assisted Laser Desorption Ionization Time-of-Flight Mass Spectrometry: A Powerful Tool for the Mass and Sequence Analysis of Natural and Modified Oligonucleotides. Nucleic Acids Res. 1993, 21, 3191-3196.

2. Smirnov, I.P.; Roskey, M.T.; Juhasz, P.; Takach, E.J.; Martin, S.A.; Haff, L.A. Sequencing Oligonucleotides by Exonuclease Digestion and Delayed Extraction Matrix-Assisted Laser Desorption Ionization Time-of-Flight Mass Spectrometry. Anal. Biochem. 1996, 238, 19-25.

3. Fitzgerald, M. C.; Zhu, L.; Smith, L. M. The Analysis of Mock DNA Sequencing Reactions Using Matrix-Assisted Laser Desorption/Ionization Mass Spectrometry. Rapid Commun. Mass Spectrom. 1993, 7, 895-897.

4. Wu, K.J.; Steding, A.; Becker, C.H. Matrix-Assisted Laser Desorption Time-of-Flight Mass Spectrometry of Oligonucleotides Using 3-hydroxypicolinic Acid as an Ultraviolet-sensitive Matrix. Rapid Commun. Mass Spectrom. 1993, 7, 142-146.

5. Tang, K.; Allman, S.L.; Chen, C.H. Matrix-Assisted Laser Desorption Ionization of Oligonucleotides with Various Matrices. Rapid Commun. Mass Spectrom. 1993, 7, 943-948.

6. Tang, K.; Taranenko, N.I.; Allman, S.L.; Chen, C.H.; Chàng, L.Y.; Jacobson, K.B. Picolinic Acid As a Matrix for Laser Mass Spectrometry of Nucleic Acids and Proteins. Rapid Commun. Mass Spectrom. 1994, 8, 673-677.

7. Currie, G.J. Yates; III, J.R. Analysis of Oligodeoxynucleotides by Negative-Ion Matrix-Assisted Laser Desorption Mass Spectrometry. J. Am. Soc. Mass Spectrom. 1993, 4, 955-963.

8. Walker, K.L.; Chiu, R.W.; Monnig, C.A.; Wilkins, C.L. Off-Line Coupling of Capillary Electrophoresis and Matrix-Assisted Laser Desorption/Ionization Time-of-Flight Mass Spectrometry. Anal. Chem. 1995, 67, 4197-4204.

9. Tang, K.; Taranenko, N.I.; Allman, S.L.; Chàng, L.Y.; Chen, C.H. Detection of 500-Nucleotide DNA by Laser Desorption Mass Spectrometry. Rapid Commun. Mass Spectrom. 1994, 8, 727-730.

10. Spengler, B. Post-Source Decay Analysis in Matrix-Assisted Laser Desorption/Ionization Mass Spectrometry of Biomolecules. J. Mass Spectrom. 1997, 32, 1019-1036.

11. Kaufmann, R.; Chaurand, P.; Kirsch, D.; Spengler, B. Postsource Decay and Delayed Extraction in Matrix-assisted Laser Desorption/Ionization-Reflectron Time-of-Flight Mass Spectrometry. Are There Trade-offs? Rapid Commun. Mass Spectrom. 1996, 10, 1199-1208.

12. Li, L.Y.C.; Cheng, S-W.; Chan, T.W.D. Evaluation of Ammonium Salts As Co-Matrices for Matrix-Assisted Laser Desorption/Ionization Mass Spectrometry of Oligonucleotides. Rapid Commun. Mass Spectrom. 1998, 12, 993-998.

13. Koster, C.; Castoro, J.A.; Wilkins, C.L. High-Resolution Matrix-Assisted Laser Desorption/Ionization of Biomolecules by Fourier Transform Mass. J. Am. Chem. Soc. 1992, 114, 75727574.

14. Nordhoff, E.; Cramer, R.; Karas, M.; Hillenkamp, F.; Kirpekar, F.; Kristiansen, K.; Roepstorff, P. Ion Stability of Nucleic Acids in Infrared Matrix-Assisted Laser Desorption/Ionization Mass Spectrometry. Nucleic Acids Res. 1993, 21, 3347-3357.

15. Szilágyi, Z.; Varney, J.E.; Derrick, P.J.; Vékey, K. Dependence of Matrix-Assisted Laser Desorption/Ionization Post-Source Decay Spectra on Laser Power. Rapid Commun. Mass Spectrom. 1998, 12, 489-492.

16. Kooman, J.M.; Russell, W.K.; Hettick, J.M.; Russell, D.H. Improvement of Resolution, Mass Accuracy, and Reproducibility in Reflected Mode DE-MALDI-TOF Analysis of DNA Using Fast Evaporation-Overlayer Sample Preparations. Anal. Chem. 2000, 72, 3860-3866.

17. Nordhoff, E.; Karas, M.; Cramer, R.; Hahner, S.; Hillenkamp, F.; Kirpekar, F.; Lezius, A.; Muth, J.; Meier, C.; Engels, J.W. Direct Mass Spectrometric Sequencing of Low-Picomole Amounts of Oligodeoxynucleotides with Up To 21 Bases by Matrix-Assisted Laser Desorption/Ionization Mass Spectrometry. J. Mass Spectrom. 1995, 30, 99-112.

18. Tang, W.; Nelson, C.M.; Zhu, L.; Smith, L.M. Positive Ion Formation in the Ultraviolet Matrix-Assisted Laser Desorption/Ionization Analysis of Oligonucleotides by Using 2,5Dihydroxybenzoic Acid. J. Am. Soc. Mass Spectrom. 1997, 8, 218-224.

19. Zhu, Y.F.; Chung, C.N.; Taranenko, N.I.; Allman, S.L.; Martin, S.A.; Haff, L.; Chen, C.H. The Study of 2,3,4-Trihydroxyacetophenone and 2,4,6-Trihydroxyacetophenone as Matrices for DNA Detection in Matrix-assisted Laser Desorption/Ionization Time-of-Flight Mass Spectrometry. Rapid Commun. Mass Spectrom. 1996, 10, 383-388.

20. Zhu, Y.F.; Taranenko, N.I.; Allman, S.L.; Taranenko, N.V.; Martin, S.A.; Haff, L.; Chen, C.H. Oligonucleotide Sequencing by Fragmentation in Matrix-Assisted Laser Desorption/Ionization Time-of-Flight Mass Spectrometry. Rapid Commun. Mass Spectrom. 1997, 11, 897-903.

21. McLuckey, S.A.; Habibi-Goudarzi, S. Decompositions of Multiply Charged Oligonucleotide Anions. J. Am. Chem. Soc. 1993, 115, 12085-12095.

22. Wang, Z.; Wan, K.X.; Ramanathan, R.; Taylor, J.S.; Gross, M.L. Structure and Fragmentation Mechanisms of Isomeric T-Rich Oligodeoxynucleotides: A Comparison of Four Tandem Mass Spectrometric Methods. J. Am. Soc. Mass Spectrom. 1998, 9, 683-691.

23. Stemmler, E.A.; Buchanan, M.V.; Hurst, G.B.; Hettich, R.L. Analysis of Modified Oligonucleotides by Matrix-Assisted Laser Desorption/Ionization Fourier Transform Mass Spectrometry. Anal. Chem. 1995, 67, 2924-2930.

24. Wan, K.X.; Gross, M.L. Fragmentation Mechanisms of Oligodeoxynucleotides: Effects of Replacing Phosphates with Methylphosphonates and Thymines with Other Bases in Trich Sequences. J. Am Soc. Mass Spectrom. 2001, 12, 580-589.

25. Christian, N.P.; Reilly, J.P.; Mokler, V.R.; Wincott, F.E.; Ellington, A.D. Elucidation of the Initial Step of Oligonucleotide Fragmentation in Matrix-Assisted Laser Desorption/Ionization Using Modified Nucleic Acids. J. Am Soc. Mass Spectrom. 2001, 12, 744-753.

26. Klassen, J.S.; Schnier, P.D.; Williams, E.R. Blackbody Infrared Radiative Dissociation of Oligonucleotide Anions. J. Am. Soc. Mass Spectrom. 1998, 9, 1117-1124.

27. Rodgers, M.T.; Campbell, S.; Marzluff, E.M.; Beauchamp, J.L. Low-Energy Collision-Induced Dissociation of Deprotonated Dinucleotides: Determination of the Energetically Favored Dissociation Pathways and the Relative Acidities of the Nucleic Acid Bases. Int. J. Mass Spectrom. Ion Proc. 1994, 137, 121-149.

28. Hettich, R.L.; Stemmler, E.A. Investigation of Oligonucleotide Fragmentation with Matrix-assisted Laser Desorption/Ionization Fourier-Transform Mass Spectrometry and Sustained 
Off-resonance Irradiation. Rapid Commun. Mass Spectrom. 1996, $10,321-327$

29. Gross, J.; Leisner, A.; Hillenkamp, F.; Hahner, S.; Karas, M.; Schäfer, J.; Lützenkirchen, F.; Nordhoff, E. Investigations of the Metastable Decay of DNA under Ultraviolet MatrixAssisted Laser Desorption/Ionization Conditions with PostSource-Decay Analysis and Hydrogen/Deuterium Exchange. J. Am. Soc. Mass Spectrom. 1998, 9, 866-878.

30. Gross, J.; Hillenkamp, F.; Wan, K.X.; Gross, M.L. Metastable Decay of Negatively Charged Oligodeoxynucleotides Analyzed with Ultraviolet Matrix-Assisted Laser Desorption/ Ionization Post-Source Decay and Deuterium Exchange. J. Am. Soc. Mass Spectrom. 2001, 12, 180-192.

31. Zhu, L.; Parr, G.R.; Fitzgerald, M.C.; Nelson, C.M.; Smith, L.M. Oligodeoxynucleotide Fragmentation in MALDI/TOF Mass Spectrometry Using 355-nm Radiation. J. Am. Chem. Soc. 1995, $117,6048-6056$.

32. Tang, W.; Nelson, C.M.; Zhu, L.; Smith, L.M. Positive Ion Formation in the Ultraviolet Matrix-Assisted Laser Desorp-
tion/Ionization Analysis of Oligonucleotides by Using 2,5Dihydroxybenzoic Acid. J. Am. Soc. Mass Spectrom. 1997, 8, 218-224.

33. Vestal, M.L. Ionization Techniques for Nonvolatile Molecules. Mass Spectrom. Rev. 1983, 2, 447-480.

34. Johnson, R.E.; Sundqvist, B.U.R. Laser-Pulse Ejection of Organic Molecules from a Matrix: Lessons from Fast-IonInduced Ejection. Rapid Commun. Mass Spectrom. 1991, 5, 574-578.

35. Antoniewicz, P.R. Model for Electron- and Photon-Stimulated Desorption. Phys. Rev. B: Condens. Matter 1980, 21, 38113815.

36. Balazs, L.; Gijbels, R.; Vertes, A. Expansion of Laser-Generated Plumes Near the Plasma Ignition Threshold. Anal. Chem. 1991, 63, 314-320.

37. Vertes, A.; Gijbels, R.; Levine, R.D. Homogeneous Bottleneck Model of Matrix-Assisted Ultraviolet Laser Desorption of Large Molecules. Rapid Commun. Mass Spectrom. 1990, 4, $228-233$. 